\title{
Brief interventions for reducing alcohol consumption in users of a family health unit
}

Intervenções breves na redução do consumo de álcool em utentes de uma unidade de saúde familiar

Intervenciones breves en la reducción del consumo de alcohol en usuarios de una unidad de salud familiar

Filomena Margarida Jorge*; Maria Teresa Moreira**; Maria Odete Pereira***;

Tereza Maria Mendes Diniz de Andrade Barroso ${ }^{* * * *}$

\begin{abstract}
Background: The primary objective of brief interventions (BIs) is to detect hazardous and harmful alcohol consumption and encourage behavior change.

Objectives: To assess the effect of BIs in reducing alcohol consumption in users of a Family Care Unit (FCU).

Methodology: A pre-experimental study, with assessment before and after the intervention (5 months), was conducted with 45 users of a FCU (single group). The Alcohol Use Disorder Identification Test (AUDIT) was used. The BIs were developed by nurses.

Results: At baseline, $88.6 \%$ of users were at risk level I and $11.4 \%$ were at risk level II. At follow-up (5 months after BIs), $97.7 \%$ of them were at risk level I and $2.3 \%$ were at risk level II.

Conclusion: BIs reduced and stabilized the risk levels of alcohol consumption, reinforcing the importance of their application in primary care.
\end{abstract}

Keywords: alcoholism; evaluation of the efficacy-effectiveness of interventions; alcohol drinking; primary health care; nursing

\section{Resumo}

Enquadramento: As intervençóes breves (IBs) têm como objetivo primordial a deteção de consumo de risco e nocivo de bebidas alcoólicas e motivar o indivíduo a modificar comportamentos.

Objetivos: Avaliar o efeito das IBs na redução do consumo de álcool em utentes de uma unidade de saúde familiar (USF).

Metodologia: Estudo pré-experimental, avaliação antes e após intervenção (5 meses) de 45 utentes (grupo único). Utilizou-se o Alcohol Use Desorder Identification Test (AUDIT). As IBs foram desenvolvidas por enfermeiros. Resultados: $\mathrm{Na}$ avaliação inicial, $88,6 \%$ dos utentes encontravam-se no nível de risco I; 11,4 \% no nível de risco II. No seguimento, 5 meses após as IBs, 97,7 \% encontravam-se no nível de risco I, 2,3\% no nível de risco II.

Conclusão: As IBs tiveram efeito na diminuição e estabilização dos níveis de risco de consumo de álcool, reforçando a importância da sua aplicação nos cuidados de saúde primários.

Palavras-chave: alcoolismo; avaliação de eficácia-efetividade das intervençóes; consumo de bebidas alcoólicas; atenção primária em saúde; enfermagem

*MSc., RN, Community Care Unit Nabão, Health Center of Ansião, 3000-457, Coimbra, Portugal [gigijorge@gmail.com]. Contribution to the article: literature search, data collection, data treatment, data analysis and discussion, article writing.

**Ph.D., Adjunct Professor, University Fernando Pessoa, 4249-004, Porto, Portugal [m.teresa.moreira@gmail.pt]. Contribution to the article: data analysis and discus-

****: Ph.D., Adjunct Professor, Federal University of Minas Gerais, 30130-100, Minas Gerais, Brazil [m.odetepereira@gmail.com]. Contribution to the article: data analysis and discussion, article writing.

****Ph.D., Adjunct Professor, Nursing School of Coimbra, Coimbra, Portugal [tbarroso@ esenfc.pt. . Contribution to the article: literature search, data collection, data treatment, data analysis and discussion, article writing. Address for correspondence: Rua Comercial, $\mathrm{n}^{\circ} 18$, Bairro da Liberdade, 3020-112, Coimbra, Portugal.

\section{Resumen}

Marco contextual: Las intervenciones breves (IBs) tienen como objetivo primordial la detección de consumo de riesgo y nocivo de bebidas alcohólicas, así como motivar al individuo para que modifique sus comportamientos.

Objetivos: Evaluar el efecto de las IBs en la reducción del consumo de alcohol en usuarios de una Unidad de Salud Familiar (USF).

Metodología: Estudio preexperimental, evaluación antes y después de la intervención (5 meses) de 45 usuarios (grupo único). Se utilizó el Alcohol Use Desorder Identification Test (AUDIT). Las IBs las desarrollaron enfermeros.

Resultados: En la evaluación inicial, el 88,6 \% de los usuarios se encontraban en el nivel de riesgo I; el 11,4 $\%$ en el nivel de riesgo II. En el seguimiento, 5 meses después de las IBs, 97,7 \% se encontraban en el nivel de riesgo I, el 2,3\% en el nivel de riesgo II.

Conclusión: Las IBs tuvieron un efecto en la disminución y estabilización de los niveles de riesgo de consumo de alcohol, y reforzaron la importancia de su aplicación en la atención de salud primaria.

Palabras clave: alcoholismo; evaluación de eficacia-efectividad de intervenciones; consumo de bebidas alcohólicas; atención primaria de salud; enfermería

Received for publication: 09.05.17 Accepted for publication: 05.07 .17

Série IV - n. ${ }^{0} 14$ - JUL./AGO./SET. 2017 


\section{Introduction}

Harmful alcohol consumption has an important social burden and economic worldwide, and it is among the five major risk factors for disabling diseases and death. Alcohol consumption patterns and alcohol-related problems vary around the world, and several factors are important to explain these differences, namely culture and availability and accessibility of alcohol (World Health Organization, 2014).

In Portugal, the per capita consumption in the adult population is 12.4 liters of pure alcohol, which is above the European average. Recent epidemiological data show a decreasing trend in consumption among the general population; however, hazardous and harmful consumption has increased in certain age groups (Balsa, Vital, \& Urbano, 2013).

Brief interventions (BIs) for the reduction of harmful alcohol consumption are strategies based on motivational approaches aimed at identifying the risk levels of alcohol consumption and helping individuals to change their behaviors, that is, to reduce or stop alcohol consumption (Babor, Higgins-Biddle, Saunders \& Monteiro, 2001; Barroso, Rosa, Jorge, \& Gonçalves, 2012; Tariq, Van den Berg, Hoogenveen, \& Van Baal, 2009; Ribeiro, 2011).

According to Ribeiro (2011), approximately $20 \%$ to $30 \%$ of people who use primary health care (PHC) units are heavy drinkers. On the other hand, there is accumulated scientific evidence on the reduction of consumption after BIs (O’Donnell et al., 2014; Platt et al., 2016).

Therefore, primary care nurses occupy a privileged position for the early detection of patterns of hazardous and/or harmful alcohol consumption among users and the development of BIs according to the identified risk levels.

In Portugal, the Directorate-General for Health has issued guidelines recommending the use of BIs, namely Norm no. 030/2012 of 28 December, updated on 18 December 2014 (Direção-Geral da Saúde [DGS], 2014). Despite this, BIs are not widely used in clinical practice and the studies in this field are scarce. The objective of this study was to assess the effect of BIs in reducing hazardous and/or harmful alcohol consumption in users of a family care unit (FCU).

\section{Background}

PHC was defined as the first level of health care at the Alma-Ata conference. PHC professionals are on the front line, are integrated in community itself, and are responsible for intervening in various areas, including health education, immunization, environmental health, family planning, maternal and child health, school health, diagnosis and treatment of the most prevalent acute and chronic diseases in the community, and supply of essential medicines.

With regard to the early detection of alcohol consumption, according to Ribeiro (2011), three major barriers must be overcome: users' difficulty to report their consumption, health professionals' difficulty to approach users, and the system's inadequacy to facilitate this detection.

According to Biscaia et al. (2008), PHC is essential and therefore should be universally accessible to all individuals and families in the community, as its main purpose is to address the community's major health problems and deliver health promotion and prevention interventions, as well as curative, rehabilitation, and end-of-life care.

In the Portuguese health system, PHC is the first level of access of individuals, families, and communities to the health system. At this lev$\mathrm{el}$, it is recommended to develop specific interventions based on the main health determinants throughout the life cycle.

With the purpose of achieving the early diagnosis and intervention among users presenting harmful or hazardous consumption or alcohol dependence, screening instruments and specific motivation-based BIs should be used based on the identified risk level (DGS, 2014).

PHC professionals occupy a privileged position and play a key role in the identification and screening of individuals with hazardous and harmful alcohol consumption, and/or likely alcohol dependence for adequate evaluation, diagnosis, and treatment interventions. These professionals can also play a role in the 
referral of individuals with alcohol dependence for treatment (Babor et al., 2001).

Nurses provide integral and personalized care to individuals and families throughout their lifecycle, in various contexts (at home or in the community) and at different levels: promotion, prevention, treatment, and rehabilitation. They promote and maintain connections between individuals, families, communities, and the rest of the health care system, working both autonomously and in cooperation to prevent diseases and disability, as well as to promote, improve, maintain, and restore health. Since 2011, the Referral/Articulation Network for Alcohol-related Problems (Rede de Referenciação/Articulação para os Problemas Ligados ao Alcool) recommends the use of specific screening instruments, namely the Alcohol Use Disorder Identification Test (AUDIT), for the detection of hazardous and harmful alcohol consumption, as well as the implementation of BIs according to identified risk levels and the referral for diagnosis in identified cases of likely dependence (Ministério da Saúde, Instituto da Droga e da Toxicodependência, 2011).

BIs have a good cost/benefit ratio (Tariq et al., 2009; Platt et al., 2016). In addition to their short duration, they follow a structured intervention protocol divided into a short sequence of steps. They use pedagogical material and can be easily included in PHC screening consultations (Babor et al., 2001; Barroso et al., 2012; Rosa, Abreu \& Barroso, 2015; Patrício, Finnell, \& Barroso, 2016).

Therefore, screening for hazardous and harmful alcohol consumption and BIs are important resources for nurses, especially in PHC (Barroso, Castanhola, Marta, \& Claro, 2010; Gonçalves, Ferreira, Abreu, Pillon, \& Jezus, 2011).

\section{Hypothesis}

Individuals undergoing $\mathrm{BIs}$ show a positive evolution in their risk level of alcohol consumption.

\section{Methodology}

A quantitative, pre-experimental study was conducted with assessment before and after BIs (5 months) on a single group.

The study was conducted in a FCU located in the Municipality of Coimbra, Portugal, using a nonprobability accidental sample. This sample was composed of registered users who attended this FCU for any reason during the study period, and agreed to participate in the study. Before data collection, consent was obtained from the institution's board of directors and all participants.

Data were collected through individual semi-structured interviews, with questions on the participants' sociodemographic characteristics and lifestyles, including the following parameters: blood pressure, body mass index, practice of physical exercise, smoking habits, and consumption of alcohol and other psychoactive substances. The risk level of alcohol consumption was determined using the AUDIT (Babor et al., 2001), which is a screening questionnaire that is used worldwide. It was developed by World Health Organization (WHO) in the 1980s with the main purpose of identifying the risk of alcohol consumption in different health services and contexts. Its use is recommended in the National Plan for Reducing Addictive Behaviors and Dependencies (Serviço de Intervenção nos Comportamentos Aditivos e nas Dependências, 2013) and Norm no. 30 of the Directorate-General for Health (DGS, 2014).

The AUDIT was validated to Portugal by Cunha (2002) and its sensitivity varies between $92 \%$ and $98 \%$. In order to verify the reliability of the AUDIT, Cronbach's alpha coefficient was calculated to assess its internal consistency. In the initial evaluation, a Cronbach's alpha value of 0.736 was obtained and the item-total correlation scores varied between -0.153 and 0.747 .

The AUDIT allows identifying hazardous and harmful consumption and likely dependence (Babor et al., 2001). It includes 10 questions on the consumption pattern and its consequences in the past 12 months: the first three questions are about characterization of consumption and hazardous alcohol use, the next three questions are about dependence symptoms, and the last four questions are about harmful alcohol use. The first eight questions are scored between 0 and 4 points and the last 
two questions are scored 0,2 , and 4 points. The total AUDIT score ranges between 0 and 40. The highest scores indicate problems. It allows determining four risk zones: Zone I (up to 7 points: indicates low risk or abstinence); Zone II (8 to 15 points: indicates hazardous risk); zone III (16 to 19 points: suggests harmful risk); and zone IV (above 20 points: suggests dependence). If the AUDIT scores are above 20, which suggest alcohol dependence, the user should be promptly referred for clinical evaluation (Babor et al., 2001).

Zone I is defined as a low risk level of consumption; zone II - hazardous consumption - is defined as the type of consumption that, despite the absence of clinical symptoms, may lead to health problems if it continues; and zone III - harmful consumption - is defined as the consumption pattern that causes physical and mental damage, but does not meet the criteria for alcohol dependence.

Based on the identified risk levels, BIs were implemented following the protocol adapted from Babor et al. (2001). Users with low risk consumption (level I; score $0-7$ ) received an educational intervention; users with hazardous consumption (level II; score 8-15) received simple advice; users with harmful consumption (level III; score 16-19) received simple advice plus brief counseling plus continued monitoring; and users with risk levels IV (20-40) were referred for diagnosis, evaluation, and treatment. For each risk level, scripts were prepared for the BIs, taking into account certain patterns such as language and approach. BIs were developed based on structured scripts that were adapted from Babor et al. (2001) within the scope of the Health without Reservations (Saúde sem Reservas) project which is registered in the Health Sciences Research Unit: Nursing. Table 1 shows how risk levels are determined based on the AUDIT scores and the interventions to be developed.

Table 1

General guidelines for risk level determination based on the AUDIT Score, and intervention to be developed

\begin{tabular}{llc}
\hline Risk level & Intervention & AUDIT Score \\
\hline Zone I & Education & $0-7$ \\
Zone II & Simple Advice & $8-15$ \\
Zone III & Simple advice + Brief counseling + Continued monitoring & $16-19$ \\
Zone IV & Referral to Specialist for Diagnostic Evaluation and Treatment & $20-40$ \\
\hline
\end{tabular}

Note. Adapted from Babor et al. (2001).

\section{Exclusion criteria}

Likely dependence and/or dependence. In the screening phase, a user was identified with likely dependence and referred for diagnosis. This user was not included in the subsequent assessment.

Data were analyzed using the Statistical Package for the Social Sciences (SPSS), version 17.0. Based on the results of the Shapiro-Wilk normality tests (for a sample with less than 50 subjects), all dependent variables call into question the assumptions of normality due to the type of study variable (alcohol consump- tion risk levels) and the type of sample (paired sample). The Wilcoxon non-parametric test was used to assess the effect of BIs.

\section{Results}

The sample was composed of 44 individuals aged between 22 and 72 years, with a mean age of 48 years $(S D=15.062)$. Most participants were men (57\%); 63.6\% had the basic education; $68 \%$ were married; and $96 \%$ lived with their family (Table 2). 
Table 2

Sample characterization according to sociodemographic variables

\begin{tabular}{|c|c|c|c|}
\hline \multirow{2}{*}{\multicolumn{2}{|c|}{ Sociodemographic characteristics }} & \multicolumn{2}{|c|}{ Sample $(n=44)$} \\
\hline & & $N$ & $\%$ \\
\hline \multirow{2}{*}{ Gender } & Male & 25 & $56.8 \%$ \\
\hline & Female & 19 & $43.2 \%$ \\
\hline \multirow{3}{*}{ Employment situation } & Employed & 30 & $68.2 \%$ \\
\hline & Unemployed & 4 & $9.1 \%$ \\
\hline & Retired & 10 & $22.7 \%$ \\
\hline \multirow{5}{*}{ Education level } & $1^{\text {st }}$ cycle of basic education & 14 & $31.8 \%$ \\
\hline & $2^{\text {nd }}$ cycle of basic education & 6 & $13.6 \%$ \\
\hline & $3^{\text {rd }}$ cycle of basic education & 8 & $18.2 \%$ \\
\hline & Secondary education & 12 & $27.3 \%$ \\
\hline & Higher education & 4 & $9.1 \%$ \\
\hline \multirow{2}{*}{ Living arrangements } & Family & 42 & $95.5 \%$ \\
\hline & Alone & 2 & $4.5 \%$ \\
\hline
\end{tabular}

Based on the AUDIT scores and the previously established protocol, 39 educational interventions and five simple advice interventions were developed. One user with likely dependence was referred and excluded from the assessment. The results obtained in the initial assessment using the AUDIT were descriptively analyzed concerning the experience of alcohol consumption so as to answer the following question: How often do you drink alcoholic beverages? This analysis showed that only $11.4 \%$ of the participants reported not to drink alcohol, whereas the remaining participants drank alcohol, with $43 \%$ of them reporting to drink alcohol four or more times per week.

With regard to the number of alcoholic beverages drank on an ordinary day, $66 \%$ of the participants answered one or two, $23 \%$ answered three or four, and $4.5 \%$ answered seven to nine drinks. Thus, 34\% reported drinking above the low risk level on a daily basis.

As regards the frequency of binge drinking, which was analyzed through the question on the consumption of six or more drinks on one occasion, $27.3 \%$ of the participants reported this type of problematic consumption.

With regard to feelings of guilt or remorse after drinking alcohol, $7 \%$ of the respondents reported having felt remorse.

\section{Effect of BIs in the first AUDIT domain}

With regard to the first domain on the characterization of consumption, the results obtained in the first question concerning the frequency of alcohol consumption showed that, in the first assessment, $43.2 \%$ of the participants drank alcohol four or more times per week. In the second assessment, after the intervention, the frequency of weekly consumption decreased to $27.3 \%$.

In the first assessment, the following results were obtained in the second question on the number of alcoholic beverages consumed on a daily basis: $6.8 \%$ and $4.5 \%$ of the participants answered five or six and seven to nine, respectively; $22.7 \%$ answered three or four, and $65.9 \%$ answered one or two.

In the second assessment, after the intervention, the number of alcoholic beverages drank on a daily basis decreased. None of the participants answered seven to nine; $2.3 \%$ and $4.5 \%$ of participants answered five or six and three or four, respectively; and 93.2\% answered one or two.

With regard to the third question on the frequency of binge drinking, defined as the 
excessive alcohol consumption (six or more drinks) on one occasion, the following results were obtained. In the first assessment, 4.5\% of participants answered weekly; $6.8 \%$ of them answered monthly; and $13.6 \%$ answered less than monthly. In the second assessment, after the intervention, none of the users answered weekly; $2.3 \%$ answered monthly (a lower percentage when compared to the first assessment); and 15.9\% answered less than monthly. These results show a decrease in the frequency of binge drinking.

Effect of BIs in the second AUDIT domain No case was identified in the first or second assessment concerning the question on impaired control over the consumption of alcoholic beverages, as well as in the fifth question on alcohol-related limitations and in the sixth question on the need to drink alcohol early in the morning to cure a hangover.

\section{Effect of BIs in the third AUDIT domain}

Finally, in the third dimension of the AUDIT, which analyzes the consequences of alcohol consumption, the seventh question assesses guilt after drinking. In the first assessment, $6.9 \%$ of participants reported this type of feelings daily or almost daily, monthly, and less than monthly. In the second assessment, there was a slight change, with no respondent answering monthly.

With regard to the eighth question on the occurrence of blackouts, only one respondent answered less than monthly (2.3\%) in the second assessment.

In the ninth question on acts committed by individuals with consequences for themselves or others as a result of alcohol consumption, $2.3 \%$ of the participants reported this occurrence in both assessments.

Finally, in the tenth question on the concern expressed by others about his/her drinking, none of the participants reported concern by others about his/her drinking patterns, that is, in both assessments.

\section{Effect of BIs in risk levels}

The analysis of the identified risk levels showed that, in the first assessment, $88.6 \%$ of the participants were at risk level I (low risk) and $11.4 \%$ were at risk level II (harmful risk). In the second assessment, after the BIs, the number of harmful drinkers decreased (2.3\%), while the number of low-risk drinkers increased $(97.7 \%)$. None of the respondents were at risk level III. In the initial assessment, one individual was identified as being at risk level IV (likely dependence). As already mentioned, the participant was excluded and referred to the family doctor who diagnosed and referred the user to a specialized unit (Table 3).

Table 3

Effect of BIs pre-and post-intervention according to the percentage of users per risk level

\begin{tabular}{lcc}
\hline Risk level & Pre-intervention $(\%) n$ & Post-intervention $(\%) n$ \\
\hline Zone I & $(88.6 \%) 39$ & $(97.7 \%) 43$ \\
Zone II & $(11.4 \%) 5$ & $(2.3 \%) 1$ \\
Zone III & 0 & 0 \\
Zone IV & 0 & 0 \\
\hline
\end{tabular}

Based on the results (before and after BIs), as shown in Table 4 on the evolution of the risk level, 43 users had a positive evolution of the risk level, that is, the risk level after the intervention is lower than the risk level before the intervention. No participant in this sample increased the risk level and only one participant maintained the risk level after the intervention. This positive evolution was statistically significant $(z=-5.712 ; p=0.000)$, indicating a positive effect of BIs in reducing risk consumption. 
Table 4

Evolution of the risk level in the sample before and after the BIs

\begin{tabular}{llccc}
\hline & \multicolumn{1}{l}{ Ranks } & Frequencies & $z$ & $p$ \\
\cline { 2 - 3 } $\begin{array}{l}\text { Level of risk after/ } \\
\text { Level of risk before }(n=44)\end{array}$ & Negatives & $43^{\mathrm{a}}$ & & \\
\cline { 2 - 3 } & Positives & $0^{\mathrm{b}}$ & & .046 \\
\cline { 2 - 3 } & Ties & $1^{\mathrm{c}}$ & \\
\hline
\end{tabular}

Note. ${ }^{\mathrm{a}}$ Level of risk after $<$ Level of risk before. ${ }^{\mathrm{b}}$ Level of risk after $>$ Level of risk before. ${ }^{\mathrm{c}}$ Level of risk after $=$ Level of risk before.

\section{Discussion}

With regard to the sociodemographic characteristics of the sample, the data obtained indicate the following profile: man, mean age of 48 years, married, living with the family, employed, and having basic education.

Results show that 43 individuals reduced their risk level and only one individual maintained the same risk level (zone II), thus confirming the positive effect of the intervention in reducing the risk level. In addition, although it was not part of the study, it is important to mention the clinical effect of screening for risk consumption since it allowed identifying one individual with likely dependence who was referred for diagnosis and treatment.

The decrease in the risk levels as a result of the intervention was mainly due to a reduction in the number of beverages consumed, frequency of consumption, and binge drinking pattern. The reduction in the binge drinking pattern is an important indicator of the effectiveness of this strategy, particularly because this type of problematic consumption, which is defined by the AUDIT as the consumption of six or more alcoholic drinks on one occasion, is an indicator of current and future problems.

Results demonstrate the effect of BIs in reducing the risk level of alcohol consumption. The quantity and frequency of alcohol consumption among the sampled participants decreased and/or stabilized after the intervention. These changes in the risk level are important health gains.

These results are in line with those found in other studies that emphasize the effectiveness of BIs in reducing alcohol consumption (McCormick et al., 2010; Bartoli et al., 2014; Platt et al., 2016).

The positive effect of BIs in reducing the risk level of alcohol consumption from harmful to low should also be highlighted, thus reinforcing the importance of the early detection and implementation of BIs according to the iden- tified risk level as an effective way of reducing hazardous and harmful alcohol consumption. This is in line with the results of other studies conducted by nurses in different clinical settings (Patrício, Finnell, \& Barroso, 2016)

\section{Conclusion}

Despite the limitations arising from the lack of a control group and the small-sized and non-representative sample, the BIs developed by nurses proved to be effective in reducing alcohol consumption.

Nurses, particularly PHC nurses, play a key role in identifying and intervening among individuals presenting hazardous or harmful alcohol consumption. For this reason, these professionals must receive training on the use of this strategy to acquire the necessary skills to apply the intervention protocol. As in other procedures that nurses perform autonomously, it is essential to detect the risk of alcohol consumption early by using adequate screening tools such as the AUDIT.

The results of this study contribute to strengthen the relevance of early detection and $\mathrm{BI}$ in reducing hazardous and harmful alcohol consumption. However, further experimental studies should be conducted to consolidate the evidence and clearly demonstrate the health gains promoted by nursing care.

\section{References}

Babor, T. F., Higgins-Biddle, J. C., Saunders, J. B., \& Monteiro, M. G. (2001). The Alcohol Use Disorders Identification Test: Guidelines for use in primary health care (2nd ed.). Retrieved from http://www. talkingalcohol.com/files/pdfs/WHO_audit.pdf

Balsa, C., Vital, C., \& Urbano, C. (2013). III inquérito nacional ao consumo de substâncias psicoativas na população portuguesa 2012: Relatório preliminar. Lisboa, Portugal: Universidade Nova de Lisboa, Centro de Estudos de Sociologia. 
Barroso, T. M., Rosa, N. R., Jorge, F. M., \& Gonçalves, C. S. (2012). Drinking among adolescents and young adults: Outcome of brief intervention. $\mathrm{Al}$ coholism: Clinical and Experimental Research, 36(2), 131A. doi: 10.1111/j.1530-0277.2012.01917.x

Barroso, T., Castanhola, R., Marta, M., \& Claro, M. (2010). Effectiveness of brief alcohol interventions by clinical nurse specialists in primary care settings. Alcoholism: Clinical and Experimental Research, 34(Suppl. 3), 128A. doi: 10.1111/j.15300277.2010.01292_4.x

Bartoli, F., Carretta, D., Crocamo, C., Schivalocchi, A., Brambilla, G., Clerici, M., \& Carrà, G. (2014). Prevalence and correlates of binge drinking among young adults using alcohol: A cross-sectional survey. BioMed Research International, 2014(2014). doi: 10.1155/2014/930795

Biscaia, A. R., Martins, J. N., Carreira, M. F., Gonçalves, I. F., Antunes, A. R., \& Ferrinho, P. (2008). Cuidados de saúde primários em Portugal: Reformar para novos sucessos (2a ed.). Lisboa, Portugal: Padrôes Culturais.

Cunha, J. (2002). Validação da versão portuguesa dos Questionários AUDIT e Five Shot para identificação de consumo excessivo de álcool. Lisboa: Internato Complementar de Clínica Geral da Zona Sul.

Direção-Geral da Saúde. (2014). Deteção precoce e intervenção breve no consumo excessivo de álcool (Norma no 030/2012 de 28 de Dezembro, atualizada em 18/12/2014). Retrieved from https:// www.google.pt $/$ url sa $=t \& r c t=j \& q=\&$ esrc $=s \&-$ source $=$ web $\& c d=1 \&$ cad $=$ rja $\&$ uact $=8 \&$ ved $=0 a-$ hUKEwik3-jzuPTUAhUE8RQKHRqxDFMQFgghMAA\&url=https $\% 3 \mathrm{~A} \% 2 \mathrm{~F} \% 2 \mathrm{Fwww}$.dgs . pt $\% 2$ Fdirectrizes-da-dgs\%2Fnormas-e-circulares-normativas\%2Fnorma-n-0302012-de-28122012-png. aspx\&usg=AFQjCNGIfKfAqAL8pV64vdU3Y6eciDin6w

Gonçalves, A. M., Ferreira, P. S., Abreu, Â. M., Pillon, S. C., \& Jezus, S. V. (2011). Estratégias de rastreamento de intervençóes breves como possibilidades para a prática preventiva do enfermeiro. Revista Eletrônica de Enfermagem, 13(2), 355-360. doi: 10.5216/ree.v13i2.10502

McCormick, R., Docherty, B., Segura, L., Colom, J., Gual, A., Cassidy, P., ... Heather, N. (2010). The research translation problem: Alcohol screening and brief intervention in primary care: Real world evidence supports theory. Journal Drugs: Education, Prevention and Policy, 17(6), 732-748. doi: 10.3109/09687630903286800

Ministério da Saúde, Instituto da Droga e da Toxico- dependência. (2011) Rede de Referenciação: Articulaçâo para os problemas ligados ao álcool. Retrieved from http://www.ordemenfermeiros.pt/colegios/ Documents/RedeReferenciacaoArticulacaoProblemasLigadosAlcool.pdf

O'Donnell, A., Anderson, P., Newbury-Birch, D., Schulte, B., Schmidt, C., Reimer, J., \& Kaner, E. (2014). The impact of brief alcohol interventions in primary healthcare: A systematic review of reviews. Alcohol and Alcoholism, 49(1), 66-78. doi: 10.1093/ alcalc/agt 170

Patrício, S. M., Finnell, D. S., \& Barroso, T. (2016). Efeito das intervençôes breves na redução do consumo de álcool em indivíduos portadores do vírus da imunodeficiência humana. Revista de Enfermagem Referência, 4(11), 41-49. doi: 10.12707/RIV16052

Platt, L., Melendez-Torres, G. J., O’Donnell, A., Bradley, J., Newbury-Birch, D., Kaner, E., \& Ashton, C. (2016). How effective are brief interventions in reducing alcohol consumption: Do the setting, practitioner group and content matter?: Findings from a systematic review and metaregression analysis. BMJ Open, 6(8), e011473. doi: 10.1136/bmjopen-2016-011473

Ribeiro, C. (2011). Medicina geral e familiar e abordagem do consumo de álcool: Deteçáo e intervençôes breves no âmbito dos cuidados de saúde primários. Acta Médica Portuguesa, 24(S2), 355-368. Retrieved from http://www.actamedicaportuguesa.com/ revista/index.php/amp/article/view/1480/1066

Rosa, N., Abreu, A., \& Barroso, T. (2015). Effect of brief interventions in reducing hazardous alcohol consumption in users receiving methadone treatment. Revista de Enfermagem Referência, 4(6), $27-$ 34. doi: 10.12707/RIV14082

Serviço de Intervenção nos Comportamentos Aditivos e nas Dependências. (2013). Plano Nacional para a Redução dos Comportamentos Aditivos e das Dependências: 2013-2020. Retrieved from http:// www.sicad.pt/BK/Institucional/Coordenacao/Documents/Planos/SICAD_Plano_Nacional_Reducao_CAD_2013-2020.pdf

Tariq, L., Van den Berg, M., Hoogenveen, R. T., \& Van Baal, P. H. (2009). Cost- effectiveness of an opportunistic screening programme and brief intervention for excessive alcohol use in primary care. PLos ONE, 4(5), e5696. doi: 10.1371/journal. pone. 0005696

World Health Organization. (2014). Global status report on noncommunicable diseases: 2014. Retrieved from http://apps.who.int/iris/bitstre am/10665/148114/1/9789241564854_eng.pdf 